\title{
A construção de imagens de si em epígrafes de teses de doutorado produzidas por surdos
}

\author{
The Construction of Images of Themselves \\ in Epigraphs of Doctoral Theses Produced \\ by Deaf
}

Maria Clara Maciel de Araújo Ribeiro*

Universidade Estadual de Montes Claros

Montes Claros - Minas Gerais / Brasil

\begin{abstract}
RESUMO: A epígrafe tem sido descrita como possivelmente introdutória ao tema da pesquisa. Além disso, ela pode delinear imagens do sujeito pesquisador. A partir da Análise do Discurso (notadamente em MAINGUENEAU, 2008), este estudo investiga em que medida as imagens de sujeito pesquisador e de sujeito surdo ativista podem ser percebidas a partir de epígrafes veiculadas em teses de doutorado produzidas por surdos. Três teses foram selecionadas para análises e compreendidas como representantes de um modelo de racionalidade científica emergente (SANTOS, 2005). Nas epígrafes analisadas, os resultados indicam que tais imagens são hibridamente construídas, apesar de ser possível perceber discreta prevalência da imagem de sujeito surdo ativista.
\end{abstract}

PALAVRAS-CHAVE: epígrafe, éthos, surdos, paradigma emergente.

ABSTRACT: The epigraph has been described as possibly the introductory theme of the research. Moreover, it can draw pictures of the subject researcher. From Discourse Analysis (especially in MAINGUENEAU, 2008), this study investigates to what extent the image of fellow researcher (and fellow deaf activist) can be perceived from epigraphs aired on doctoral theses produced by deaf. Three theses were selected for analysis and included as representatives of an emerging model of scientific rationality (SANTOS, 2005). In the selected epigraphs, the results indicate that such images are constructed in a hybrid manner, although you may notice a slight prevalence of the image of the deaf activist.

KEYWORDS: epigraphs, ethos, deaf, emerging paradigm.

\footnotetext{
*mclaramaciel@hotmail.com
} 


\section{Introdução}

Atualmente, inúmeras pesquisas têm revelado a imagem que jornalistas, políticos, professores e cientistas projetam de si mesmos em seus discursos, independente de sua intencionalidade (CAVALCANTI, 2008; FERREIRA, 2009; RAMOS, 2006 e ROMUALDO, 2008). Nesse expediente, a categoria de éthos, originária da retórica aristotélica e reformulada no quadro teórico da Análise do Discurso, sobretudo por Dominique Maingueneau (2008), tem sido o principal instrumento teórico e analítico.

A partir da Análise do Discurso (AD) de orientação francesa e de contribuições da Linguística Textual (LT), o presente estudo focaliza os indícios que possibilitam a projeção de imagens de si no gênero epígrafe veiculado em teses de doutorado. As teses selecionadas guardam a particularidade de terem sido produzidas por sujeitos surdos e de projetarem, além de imagens de sujeitos pesquisadores, também imagens de sujeitos surdos ativistas, engajados em causa social própria. A partir daí, objetivo verificar em que medida cada uma dessas imagens (de sujeito pesquisador e de sujeito surdo ativista) podem ser percebidas na epígrafe.

Para tanto, na Linguística Textual (LT), Bhatia (2005) e Bezerra (2007) serão conclamados para o entendimento do gênero textual epígrafe, enquanto Maingueneau (2005, 2008), representando a Análise do Discurso (AD), será fundamental para o estudo do éthos. Além disso, Boaventura de Sousa Santos será importante para se compreender a configuração discursiva pós-moderna das teses selecionadas - configuração, aliás, motivadora das relações teóricas aqui estabelecidas, pois este estudo não se interessa pela Análise Textual stricto sensu, mas principalmente pela análise dos elementos discursivos que subjazem ao texto, motivo que me leva a eleger Maingueneau teórico mestre. Por outro lado, uma vez que, para a Análise do Discurso, todo discurso é materializado em um texto e que, por sua vez, todo texto se estabiliza em um gênero, autores da Linguística Textual, como dito,

\footnotetext{
${ }^{1}$ As relações entre AD e LT são pertinentes porque ambas abordam o objeto texto/discurso em seus empreendimentos. As divergências, que não nos parecem inconciliáveis, incluem o fato de a LT priorizar o texto, sem desconsiderar o discurso (entendido como uma unidade conjunta à categoria texto), enquanto a $\mathrm{AD}$ privilegia as relações discursivas, sem desconsiderar a materialidade textual (considerando o texto como a materialização dos discursos) (CAVALCANTE; CUSTÓDIO FILHO, 2010; FIORIN, 2010).
} 
serão indispensáveis para a compreensão das epígrafes enquanto gêneros compostos por regularidades. ${ }^{1}$

A partir do quadro teórico descrito acima, verifico, pois, o que a escolha das epígrafes diz do sujeito da pesquisa e do sujeito surdo ativista, hibridamente manifestos no decorrer das teses, conforme demonstrado em Ribeiro (2012). ${ }^{2}$

\section{Sobre a noção de éthos}

É na obra Gênese dos Discursos (1984/2005a) que Dominique Maingueneau dá início às reflexões relativas ao estudo dos modos de enunciação (maneiras de dizer e de se apresentar) que, posteriormente, irá compor a sua noção de éthos - categoria cuja origem remonta à Retórica, de Aristóteles. É nessa obra seminal que a autor traz à tona a preocupação de Bakhtin com o estudo do tom, hoje sabidamente componente do éthos, mas considerado, à época, um dos aspectos menos estudados da vida verbal - embora já vislumbrado por Todorov (1981) como "ligado à relação do locutor com a pessoa de seu parceiro" (MAINGUENEAU, 2005, p. 90).

Para definir o tom, o autor sustenta que "através dos seus enunciados, o discurso produz um espaço onde se desdobra uma 'voz' que lhe é própria” (p. 98). Essa voz própria, segundo ele, se apoia em uma dupla imagem do enunciador, que se projeta tanto a partir de evidências de seu caráter (conjuntos de traços psicológicos aparentados, como "humoral", "sanguíneo", "agressivo" etc.) quanto a partir de indícios de sua corporalidade (representação de um corpo fictício que condiga com os traços psicológicos apresentados). Caráter e corporalidade devem ser entendidos como projeçōes discursivas inseparáveis e mutuamente reclamantes.

Tom, caráter e corporalidade, portanto, definem um "modo de enunciação" específico que - lembra o autor - obedece à mesma semântica e às mesmas restrições que regem o próprio conteúdo do discurso. Diante disso, vê-se que a formulação da tríade está bem distante de um dispositivo retórico "escolhido" pelo sujeito falante diante dos objetivos de seu projeto de fala; pensa-se, pois, em atributos que podem se projetar independentemente das formulaçôes conscientes de dado locutor.

É na obra citada que Maingueneau (2005) lança as bases de sua teoria do éthos discursivo (sem ainda nomeá-lo como tal) e deixa entrever que

\footnotetext{
${ }^{2}$ Esta pesquisa é um recorte da pesquisa de doutorado realizada por Ribeiro (2012).
} 
tanto o discurso oral quanto o escrito possuem uma vocalidade específica, que pode manifestar-se por meio de um caráter e de um tom, como dito, que, por sua vez, podem ser associados a uma fonte enunciativa que remete a um "corpo enunciante" (não a um corpo efetivo, sobretudo se pensarmos nos textos escritos). Desse modo, vê-se que o éthos em Maingueneau não é pensado apenas a partir de discursos orais ou marcadamente eloquentes, mas a partir de toda troca verbal, seja oral ou escrita, uma vez que toda manifestação discursiva possui uma vocalidade específica, que permite relacioná-la a determinada fonte enunciativa, que apresenta certo caráter e certa corporalidade, desenhando uma imagem de si $^{3}$ que será (ou não) incorporada pelo auditório.

Apesar de a categoria parecer fluida, nos estudos mais recentes do autor ela aparece fortemente estabilizada pelo uso e com novas proposiçóes e problemas, dessa vez, definitivamente distante da tradição aristotélica. Atualmente, o estudo do éthos deixa entrever questóes não previstas em sua formulação inicial. A evolução dos estudos do conceito trouxe problemas de ordens distintas, uma vez que a difusão e a utilização dessa categoria nos mais variados corpora (blogs, sites de relacionamentos, discursos infantis, científicos, literários, pedagógicos...) fizeram emergir dificuldades que a complexificaram, quais sejam:

1. Sendo o éthos construído no e pelo discurso, isto é, apenas a partir da tomada da palavra pelo orador, o que fazer, então, com as imagens que compõem previamente o imaginário social do auditório a respeito do orador antes mesmo que ele tome a palavra? Pode-se prever que o auditório constrói representações do éthos do orador previamente à sua fala. Em outras palavras, lugares sociais específicos, aliados a saberes partilhados e à memória discursiva, podem levar o auditório a criar expectativas em relação ao éthos do orador. É possível, por essas razōes, construir expectativas específicas do éthos típico de um padre ou de um ativista do Greenpace, por exemplo. A enunciação, em si, é que irá confirmar ou não as imagens previamente construídas pelo auditório. É, portanto, para se referir às imagens do locutor construídas pelo auditório antes mesmo de seu turno de fala que Maingueneau apresenta a noção de éthos pré-discursivo.

2. Há, atualmente, uma distinção metodológica entre duas maneiras de apreensão

${ }^{3}$ Como se pode perceber, éthos tem sido traduzido, em português, como "imagem de si”. 
do éthos. A primeira delas é tributária de Barthes e Ducrot, autores para quem o éthos (ainda aristotélico) é apreensível unicamente por meio do modo pelo qual o orador exerce sua atividade oratória (nível da enunciação, do dizer) não a partir de informações que o orador dá de si mesmo (nível do enunciado, do dito). Como proceder, então, diante das investidas explícitas (da ordem do enunciado) do sujeito sobre si mesmo? Elas serão desconsideradas ou integrarão outro componente analítico, distinto do éthos?

O próprio Ducrot resolve essa questão por meio da distinção que estabelece entre o locutor L (ser puramente discursivo) e locutor $\lambda$ (o locutor enquanto ser do mundo). Segundo ele, além do locutor enquanto tal (L), figura puramente discursiva, é possível perceber também as manifestações desse locutor em interface com o locutor mundano (L $\lambda$ ): enquanto fonte da enunciação que o $L \lambda$ se mostrará dessa ou daquela maneira. Quando o orador se coloca na posição de objeto da enunciação, portanto, estará a falar de $\lambda$, "um tipo de figura discursiva de um ser do mundo", conforme Soulez (2008, p. 15), não do locutor enquanto tal (L). Embora o locutor L deixe entrever o locutor $\lambda$, Ducrot $(1987$, p. 189) ressalta que o thos estaria ligado apenas a L:

Na minha terminologia, direi que o éthos está ligado a L, o locutor enquanto tal: é enquanto fonte da enunciação que ele se vê dotado [...] de certos caracteres que, por contraponto, tornam esta enunciação aceitável ou desagradável. O que o orador poderia dizer de si, enquanto objeto da enunciação, diz, em contrapartida, respeito a $\lambda$, o ser no mundo, e não é este que está em questão na parte da retórica de que falo [...].

Maingueneau, contudo, considera as informações oferecidas por L $\lambda$ também contributivas e caracterizadoras de L. Se, até pouco tempo, tais ocorrências explícitas eram desconsideradas na caracterização do éthos (porque não se conseguia resolver um problema metodológico ou porque se temia ir contra a tradição aristotélica), Maingueneau (2005; 2008) alarga essa noção ao considerar, além do éthos mostrado (o "tom" do discurso), também o éthos dito, ou melhor, as informaçôes explícitas que o locutor dá se si mesmo ao auditório.

O autor propõe, então, a noção de éthos efetivo, que integra tanto um éthos pré-discursivo quanto discursivo, que se divide em éthos dito (nível do enunciado) e éthos mostrado (nível da enunciação). $\mathrm{Na}$ ampliação da noção, além do modo e do "tom" que o locutor confere ao seu discurso (éthos 
mostrado), há as ideias de si mesmo que ele apresenta (éthos dito), conforme esquema abaixo, retirado de Maingueneau (2008, p. 19):

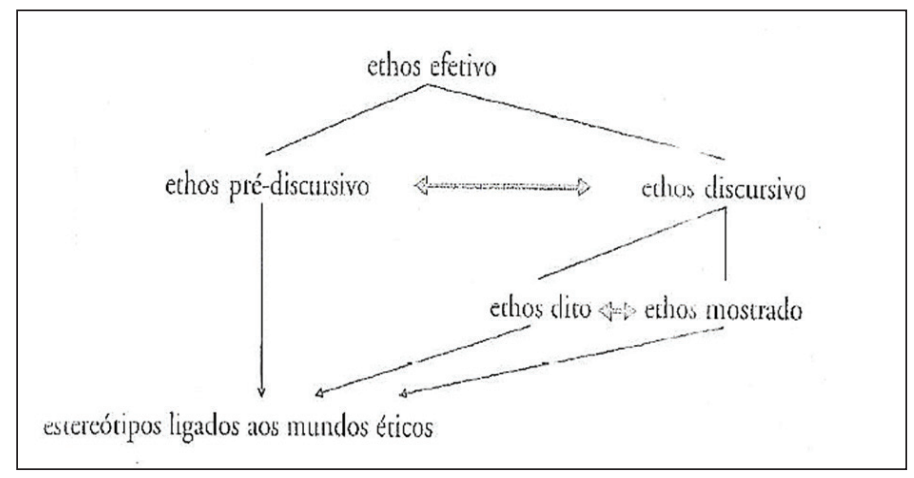

FIGURA 1 - Composição do éthos efetivo

Fonte: Maingueneau (2008, p. 19).

Vemos, pois, que a categoria é complexa e que ela engloba, segundo a figura 1: i) as imagens do Locutor construídas a partir da memória discursiva do auditório (éthos pré-discursivo); ii) as imagens de si projetadas pelo locutor a partir do momento em que este toma a palavra (éthos discursivo); iii) as imagens de si construídas por via do tom e do sugerido (éthos mostrado); iv) as imagens de si efetivadas verbalmente na estrutura do enunciado (éthos dito) e v) Enfim: todas as imagens de si (prévias, mostradas ou ditas) que sempre se estabelecem a partir dos estereótipos ligados aos contextos.

As análises partirão dessa intricada rede de possibilidades de falar de si, seja pela memória discursiva dos interlocutores, seja pelo tom e caráter expressos pelo orador ou pelas palavras claramente atribuídas a si, conforme visto.

\section{Uma sobreposição pós-moderna: um fazer acadêmico que se mescla a um fazer ativista social}

Teses produzidas por surdos guardam algumas particularidades, se comparadas ao fazer acadêmico comum. A mais importante delas talvez seja o comprometimento político e social com o próprio povo surdo, claramente manifesto nos empreendimentos acadêmicos dessa população (RIBEIRO, 2012).

Para compreender melhor essa tendência pós-moderna - guardada suas especificidades, também praticada pela intelectualidade negra sediada 
na academia (MAMA, 2010; GOMES, 2010) - apresento, a seguir, distintos modelos de racionalidade científica, ou melhor, diferentes maneiras de se pensar a produção de conhecimento na academia, na contemporaneidade.

Boaventura de Sousa Santos (2005) considera que o paradigma de racionalidade dominante na ciência moderna, da maneira que o conhecemos, está em crise. Em seu lugar, vemos amostras da erupção de um paradigma outro, emergente, ainda difuso e disforme, mas em alguma medida já vislumbrado e praticado.

O autor se refere ao modelo de racionalidade científica constituído a partir da revolução científica do século XVI, considerado por ele totalitário na medida em que nega o caráter racional às formas de conhecimento que não seguem seus princípios epistemológicos ou metodológicos, de maneira a se considerar os estudos humanísticos menos racionais ou científicos que outros.

No paradigma chamado dominante, por exemplo, dirá Santos (2005), sujeito e objeto encarnavam instâncias epistemológicas sempre distintas e distantes - fato que garantia a suposta "neutralidade científica". Atualmente, no entanto, no paradigma que emerge, discute-se a importância de se considerar no objeto a continuação do sujeito por outros meios, de forma a se considerar o conhecimento advindo dele como uma espécie de autoconhecimento, o que imputaria à produção de conhecimento um caráter quase autobiográfico:

Hoje sabemos ou suspeitamos que as nossas trajetórias de vida pessoais e coletivas (enquanto comunidades científicas) e os valores, as crenças, os prejuízos que transportam são a prova íntima do nosso conhecimento, sem o qual as nossas investigações laboratoriais ou de arquivo, os nossos cálculos ou os nossos trabalhos de campo constituiriam um emaranhado de diligências absurdas sem fio nem pavio. No entanto, este saber, suspeitado ou insuspeitado, corre hoje subterraneamente, clandestinamente, nos não-ditos de nossos trabalhos científicos (SANTOS, 2005, p. 85).

Vê-se que na ciência dita pós-moderna (paradigma emergente) o caráter autorreferenciável já não é mais dissimulado, mas assumido. A partir de uma ressubjetivação, o conhecimento se torna correlato a um saber prático de vida. É isso justamente o que se apresenta na pesquisa engendrada por surdos: o conhecimento construído caracteriza a formulação de um autoconhecimento, de um saber que também o referencia. Em grande proporção, sobretudo na área da Educação, surdos vão para a academia para pesquisar temas automotivados: falar do outro (surdo) é falar de si, na mesma medida em que demonstrar anseios e sentimentos próprios à comunidade 
surda é tocar também a sua própria inquietação.

Após a comprovação acadêmico-científica das Línguas de Sinais como línguas naturais e multiniveladas, seguida da consequente constatação de que sujeitos surdos são seres potencialmente bilíngues e da notória melhoria da educação destinada a essa população, a valorização e independência dos surdos não tem deixado de crescer em todo mundo. O estigma de deficiência está caindo por terra e cidadãos que não ouvem estão tendo oportunidades de crescimento ampliadas.

É para manterem ativas as transformações sociais em relação à compreensão do meio de vida surda que se erigem os pesquisadores surdos. A empreitada de articular pesquisa e ativismo social (que vemos em muitas teses de autoria surda) inclui não apenas o desejo de reordenar as relações de poder entre surdos e ouvintes, mas também o de reconstruir a imagem social dos surdos na sociedade, por meio de uma manobra (inter)discursiva, em que as imagens de sujeito pesquisador e de sujeito ativista se sobrepõem. Na academia, aliás, a sobreposição de papéis entre sujeito da pesquisa e sujeito pesquisado não é específica aos surdos, pois parece se estender às demais minorias sociais (negros, índios e homossexuais, por exemplo). Nestas pesquisas, a determinação do lugar social da fala do sujeito da pesquisa, a partir da epígrafe, pode ser compreendida como indício de um paradigma de racionalidade acadêmico-científica emergente, conforme postula Santos (2005).

Em estudo recente, Ribeiro (2012) desvendou a natureza da relação sujeito acadêmico e sujeito militante em teses de doutorado produzidas por surdos, mostrando as sobreposições, complementações e embates dessas facetas no fio do discurso, de tal maneira que é válido questionar: em que medida é possível perceber imagens do sujeito que pesquisa e do sujeito que milita já nas epígrafes das teses de doutorado empreendidas por surdos? As epígrafes antecipam ou omitem a configuração híbrida das teses? Três teses de doutorado (de autoria surda) foram selecionadas para a análise, conforme explicito a seguir.

\section{Descrição dos procedimentos}

Uma vez que esta pesquisa objetiva revelar imagens de si (enquanto sujeito pesquisador e enquanto sujeito ativista) construídas a partir das epígrafes, buscaram-se selecionar teses cujo engajamento social se fazia notório. Em levantamento inicial, foram encontradas sete teses de doutorado defendidas por surdos no Brasil até 2010 - todas produzidas na grande área Educação. A partir deste universo, as teses cujas temáticas predominantemente 
técnicas (portanto, menos políticas) pareciam não favorecer os objetivos da pesquisa, foram eliminadas. Ao fim, chegou-se a um corpus constituído por três teses, todas defendidas em universidades federais, em programas de pósgraduação em Educação, entre 2007 e 2010, conforme o quadro a seguir:

QUADRO 1

Seleção das teses

\begin{tabular}{|l|c|c|c|c|}
\hline \multicolumn{1}{|c|}{ Tese } & Autor & Instituição & Defesa & Sigla \\
\hline $\begin{array}{l}\text { Implante Coclear na constituição } \\
\text { dos sujeitos surdos } \\
\text { Doutorado em Educação }\end{array}$ & $\begin{array}{c}\text { REZENDE, } \\
\text { Patrícia L. Ferreira }\end{array}$ & UFSC & 2010 & T1 \\
\hline $\begin{array}{l}\text { Surdos: vestígios culturais não } \\
\text { registrados na História } \\
\text { Doutorado em Educação }\end{array}$ & STROBEL, Lílian & UFSC & 2008 & T2 \\
\hline $\begin{array}{l}\text { A Experiência e a Pedagogia } \\
\text { que nós surdos queremos } \\
\text { Doutorado em Educação }\end{array}$ & $\begin{array}{c}\text { MIRANDA, } \\
\text { Wilson Oliveira }\end{array}$ & UFRGS & 2007 & T3 \\
\hline
\end{tabular}

Epígrafes veiculadas nas teses acima serão analisadas a partir das considerações a respeito do éthos (projeção das imagens de si), estudos do gênero epígrafe e do paradigma de racionalidade científica emergente. A partir daí, pretende-se tornar claro o que a produção de epígrafes comunica da imagem que o sujeito pesquisador pretende (ou não) passar de si mesmo.

De acordo com o quadro 1, por questôes de organização metodológica, as teses serão referidas pelas siglas T1, T2 e T3, e os locutores que se expressam por meio delas serão reconhecidos pelas siglas L1, $\mathrm{L} 2 \mathrm{e} \mathrm{L3}$, respectivamente. Nas ocasiōes em que o foco estiver no Locutor $\lambda$, a referência será a $L \lambda 1, L \lambda 2, L \lambda 3$.

\section{Análises}

Bhatia (2004) tem discutido os benefícios de considerar o gênero a partir de outros gêneros com os quais ele se relaciona. Por essa perspectiva, temos que considerar que a epígrafe faz parte de uma colônia de gêneros acadêmicos cujos gêneros se delimitam reciprocamente. Trata-se de um gênero de natureza composicional híbrida que, via de regra, é suportado por outro gênero. Veremos, a seguir, que a relação estabelecida entre a epígrafe e o gênero que a suporta é determinante tanto para a composição formal quanto para o estabelecimento dos propósitos comunicativos da epígrafe. 
Para Bezerra (2007), a epígrafe se presta à função de introduzir o tema da pesquisa com uma citação de autoridade. Ela pode ser considerada um gênero bastante estereotipado e, ao mesmo tempo, potencialmente híbrido. Como veremos, o texto que cumpre a função da epígrafe e que desempenha sua funcionalidade textual, discursiva e social, pode apresentar-se como um poema, uma canção, um miniconto, uma citação de autoridade etc., de maneira a ser possível pensar no fenômeno da intergenericidade, como atesta Marcuschi (2003). A meu ver, é importante ainda ter em vista que se trata de um recorte de texto - com condições de produção e semântica própria - extraído e transportado para um lócus espacialmente diferente - com condiçôes e semânticas distintas. No gênero que serve de suporte à epígrafe (no presente caso, a tese), o excerto se prestará a propósitos comunicativos bastante diferentes dos originais -, o que lhe conferirá um caráter de gênero "transmutado", na opinião de Bezerra (2007), ou de "reversão de funções", no dizer de Marcuschi (2003).

Caracterizo brevemente o gênero que suporta as epígrafes analisadas: teses de doutorado podem ser definidas como um gênero pertencente à esfera do discurso acadêmico, cujo propósito comunicativo envolve a comunicação de resultados de uma pesquisa de doutoramento, em princípio, original e contributiva. Dudley-Evans (1998) considera a crescente pressão por programas e pesquisas interdisciplinares, aliada ao consequente abrandamento de limites entre as disciplinas, o fator responsável, ao mesmo tempo, pela dinamicidade e complexidade do discurso acadêmico contemporâneo e pelas oscilações de estilo na constituição dos gêneros dessa esfera. Nessa perspectiva, é possível considerar que algumas peculiaridades do funcionamento acadêmicocientífico da produção de teses passam por um crivo disciplinar e/ou comunitário, próprio a um lócus específico, ou melhor, a uma comunidade acadêmica dada, o que nos leva a supor que seria possível encontrar padrōes semelhantes de funcionamento genérico, em relação à produção de teses e/ou epígrafes, na comunidade acadêmica surda. Nessa perspectiva, pesquisas com mais amplitude poderiam determinar, por exemplo, se a expressão do ativismo social é característica das produções acadêmicas de autoria surda ou se se faz presente em uma pequena amostragem dessa produção.

Por ora, para a reflexão que desenvolvo, o que importa é entender a correlação de sentidos produzida entre a epígrafe e o tema de cada tese. A partir daí pensarei, a seguir, em que medida as epígrafes das teses contribuem para introduzir o tema, conferir autoridade e construir imagens do sujeito produtor da pesquisa. Vamos à epígrafe da T1: 
(01) EPÍGRAFE

Eu, Surda.

Graduada em Pedagogia eu sou

De tudo na minha vida dou valor

Saiba o que destino me dedicou

e de tão brutal força ele me jogou

no universo do qual morrerei.

Nasci em plena Caeté

terra dos Santos e da Fé

primeiro a cabeça e depois o pé

assim saí da vida como Deus quer,

formosa e guerreira serei.

É uma história tão minha unicamente

que merece ser contada parcialmente

pois há outras não relatadas intimamente

e de coração pulsando constantemente,

os discursos de bravos surdos contarei

Muitos caminhos já percorri nas estradas da vida

assim da impérvia ciência serei consumida

No começo, por toda a minha infância, ficava dividida

entre os surdos e os ouvintes, e ainda assim, no dia a dia

meu sonho foi moldando e decidi que para os surdos lutarei.

Agora, quebrarei a rima da minha dura poesia que agora contei

pois me perdi ao escrever e eram tantas vidas passadas

que vão conjugando verbos com abismos violentos que tive.

Neste momento ímpar da minha flor, assim contarei os anos

não pelos momentos que amargamente sofri

mas pelas saborosas vitórias que amealhei

nos percalços díspares que passei

no embate dos fortes, nas discrepâncias dos covardes assim me juntarei.

Reerguerei o orgulho dos surdos

e a história da fina flor amordaçada

que é a minha língua de sinais há muito violentada

será apenas um pedaço da História esquecida.

Assim sou Patrícia, sou formosa guerreira amada

Assim nasci em Caeté, terra dos Santos e da Fé

Assim da Ciência de Skliar, a aprender eu comecei

Assim nesta Ordem de Discurso de Foucault me apaixonei

Assim por amor ao Franklin, ao Amazonas irei

Assim da vida feliz, eu, Surda, morrerei.

Poesia escrita por Franklin Ferreira Rezende Jr. em 2007 (T1, s/p). 
Para Bezerra (2007, p. 206), não se trata de transformar a epígrafe em um "gênero sem nome", mas "o nome é dispensável para a sua identificação", diferentemente do que ocorre com os demais gêneros da colônia, como os agradecimentos, por exemplo, que são obrigatoriamente antecedidos pelo nome. Apesar disso, notamos a preocupação de L1 em demarcar o texto apresentado, em letras grandes e negritadas, como uma "EPÍGRAFE", situação realmente incomum.

Ora, a experiência nos mostra que são bastante raras (ou praticamente inexistentes) as ocasióes em que o título desse gênero antecede o texto. Normalmente, reconhece-se uma epígrafe diante de sua ordem nos elementos pré-textuais, de sua forma (curta e citatória) e conteúdo (quase sempre acadêmico ou literário), além da notável correlação de sentidos estabelecidos entre ela (a epígrafe) e o estudo em foco. Por que, então, a necessidade (ou o desejo) de nomear esse gênero, como o faz L1?

$\mathrm{Na}$ epígrafe em análise, vemos pelo menos duas importantes distinções em relação à maneira canônica de veiculação de epígrafes em teses: a primeira, perceptível no plano de expressão, é o uso de um poema completo, que incluiu título e mais de 280 palavras distribuídas em duas páginas, em vez de um ou dois versos ou parágrafos que costumam ocupar o fim da folha em branco. A segunda, perceptível no plano de conteúdo, diz respeito ao tema da epígrafe, que focaliza a própria autora ${ }^{4}$ da tese, em vez de apresentar uma referência teórica ou literária. Ora, esta, certamente, é uma distinção relevante e, em certa medida, até curiosa. A epígrafe traz informações do locutor $\lambda$ (locutor também discursivo, embora em interface com o locutor mundano), constrói um éthos específico (galante e determinado) e dá mostras de um atravessamento pessoal e subjetivo que fatalmente acometerá todo o estudo. Pelo que parece, são as distinções acima que levam L1 a demarcar, com letras grandes e negritadas, que o texto que virá presta-se, sim, ao papel de epígrafe.

Intitulado "Eu, surda", o poema projeta sobre L1 uma dupla imagem de $s i,{ }^{5}$ construída tanto pelo viés do éthos dito (ED) quanto pelo viés

\footnotetext{
${ }^{4} \mathrm{O}$ termo "autor(a)" designa neste estudo o(a) produtor(a) da tese em análise, ou seja, aquele que se responsabiliza e responde pela produção textual, sem outras implicações teóricas.

${ }^{5}$ Embora o poema seja assinado por outra pessoa (Franklin Ferreira Rezende Jr), o fato de ter sido assumido e reproduzido pela autora da tese (que é inclusive citada nominalmente, como se ela própria o tivesse escrito), autoriza-me a falar em "imagem de si”. O autor da epígrafe era companheiro da autora da T1, na época da produção da tese. Um surdo engajado, como ela, nos movimentos ativistas da comunidade.
} 
do éthos mostrado (EM): a primeira imagem, apreensível no plano do enunciado (ED), apresenta o eu que fala como surda, formosa e guerreira, nascida em terra de fé, destinada a ser o que é porta-voz de bravos surdos, que luta por eles, que vivenciou momentos amargos e saborosas vitórias, assim como percalços díspares e embates fortes, que se responsabiliza por reerguer o orgulho dos surdos e da língua de sinais. $\mathrm{L} \lambda 1$ nos apresenta, deste modo, uma imagem de ser surdo que rompe completamente com o éthos pré-discursivo de sujeitos surdos no senso comum. Nessa esfera, surdos ainda são considerados deficientes, apáticos, silenciosos e com especificidades cognitivas - apesar de certamente começarmos a ver pequenas alterações imagéticas, não gerais e ainda sem força definitiva, no corpo social.

Ora, o que vemos aqui são amostras do caráter da autora (L $\lambda$ ), que não hesita ou se envergonha ao se considerar, diante de uma gama de leitores, formosa e guerreira, a "assinalada", semelhante ao poema de Cruz e Souza, ${ }^{6}$ escolhida pelo destino para ser diferente. Enquanto aquele povoa com belezas um mundo despovoado, esta fala pelos seus sem fala (metaforicamente).

A segunda imagem, também apreensível pelo viés do enunciado (ED), apresenta ainda o eu que fala como uma pedagoga, cuja cabeça, em seu nascimento, antecedeu aos pés (metaforizando a vocação para o saber), que será consumida por uma ciência impérvia, que é adepta e aprendiz da ciência de Skliar, ${ }^{7}$ além de apaixonada pela ordem do Discurso de Foucault. Vemos aqui uma pedagoga que se mostra intelectual e afeita ao conhecimento científico. O adjetivo "apaixonada", uma qualificação que não costuma povoar o discurso "objetivo" e "racional" da academia, produz uma ponte entre o ser da ciência (academia) e o da língua de sinais (ativismo social), ponte que será evidenciada no decorrer da tese.

No plano da enunciação, pelo viés do éthos mostrado (EM), L1 evidencia um caráter de emotividade e pungência que se mistura a um tom dramático de busca de entendimento e de louvor a si mesma. O louvor a si

\footnotetext{
${ }^{6}$ Trata-se do poema "Assinalado": "Tu és o Poeta, o grande Assinalado/ Que povoas o mundo despovoado/ De belezas eternas, pouco a pouco.../ Na Natureza prodigiosa e rica/ Toda a audácia dos nervos justifica/ Os teus espasmos imortais de louco!" (CRUZ e SOUZA, 1984).

${ }^{7}$ Trata-se de Carlos Bernardo Skliar, professor argentino que, em estágio pós-doutoral no Brasil, orientou a Tese 3 (que compõe o corpus desta pesquisa). É conhecido por ter favorecido e fortalecido, no Brasil, um discurso acadêmico questionador e filosófico sobre o valor do outro (surdo) e da diferença.
} 
parece querer alertar o leitor quanto a imagem de quem produz a tese e busca despi-lo de qualquer éthos prévio negativo que possa vir a acompanhá-lo. E, apesar da projeção de duas imagens, a saber, a de surda ativista e engajada, por um lado, e a de pedagoga intelectual, por outro, o poema não as apresenta dissociadas, mas mescladas e sobrepostas uma à outra, de modo que, em alguns momentos, não se sabe, ao certo, a que empreendimento imagético servem alguns trechos, como em: "De tudo na minha vida dou valor"; "(...) me jogou no universo do qual morrerei"; "Muitos caminhos já percorri nas estradas da vida" (grifos meus). Neste ponto, é possível perguntar: quem dá valor, a ativista ou a pedagoga, e a que tudo se refere? De qual universo se trata: do surdo ou do acadêmico? Estradas da academia ou da comunidade? A resposta não pode ser dicotômica justamente porque o sujeito da pesquisa é constituído pelo sujeito social (e vice-versa). Apesar dessa constatação, na epígrafe, contudo, o que se vê é a imagem de "ser comunitário" (ou ativista) projetada com mais força e nitidez que a imagem de ser acadêmico.

Chama atenção ainda o caráter polifônico do poema, que é produzido em uma linha de equilíbrio entre o ficcional e o factual. Como já foi dito (ver nota 03), apesar de o poema, indubitavelmente, caracterizar a autora da tese ("eu, surda", "assim sou Patrícia") e ser possível apreender, em vários trechos, informaçóes de L $\lambda 1$ (locutor enquanto ser do mundo), quem fala aqui não é o autor empírico da tese, mas uma terceira pessoa que produz um $e u$ a partir dos olhos de outro, condição que poderia, sim, enquadrar a projeção do eu em um quadro de criação ficcional, por não ser o texto de caráter genuinamente autobiográfico. Por outro lado, o sujeito referido pelo eu endossa e afirma o texto como legítimo de caracterizá-lo, uma vez que não apenas o insere na sua tese, mas o insere completo e como epígrafe.

Isso leva o(a) analista a pensar nas correlaçóes de sentido entre a epígrafe e a tese propriamente dita. Se, em vez do poema relativo à autora, houvesse um trecho teórico ou mesmo literário, certamente seria entendido como representativo da obra ou, pelo menos, altamente significativo para o tema desenvolvido. Assim, no caso em análise, sou levada a pensar que o caráter e personalidade da autora, sua trajetória e história são significativas para a produção da tese, ou melhor, são pesos definidores da pesquisa que será apresentada. A partir da epígrafe, o leitor é convidado a espiar para além dos muros da academia, isto é, para o sujeito social por trás da produção da tese. A epígrafe é, pois, conforme a definição de Machado de Assis expressa em Esaú e Jacó, um "par de lunetas" que lança luz aos personagens; no presente 
caso, que lança luz à relação de ativismo social dos sujeitos locutores e que conclama o leitor a efetivamente interagir com a ativação de conhecimentos não linguísticos necessários para a produção de sentidos discursivo-textuais.

Afasta-se, pois, logo de início, qualquer intenção de neutralidade ou de distanciamento - considerados por muitos autores características do discurso acadêmico-científico. Ao contrário, trata-se de um ser apaixonado, emotivo e solidário, pois certamente não há aqui a simples ocorrência de um locutor puramente fictício (L), mas também de um locutor mundano, e o conteúdo do poema traz indícios da presença do locutor lambda (L $\lambda$ ) na tese. Enquanto artefato simbólico, o poema aponta, enfim, para a liberdade criativa (acadêmica?) e emancipadora da autora, que definitivamente não pretende agir segundo o status quo. Ou, por outro prisma, há aqui indícios bastante claros do rompimento com o paradigma dominante e a filiação a um modelo de racionalidade acadêmico-científica considerado emergente.

A epígrafe da T2, a seguir, também apresenta pelo menos duas facetas significativas para a discussão a ser desenvolvida:

(02) O povo surdo tem muitas faces.

A sua história se faz da realização de cada sonho de surdo.

Você também constrói a história, é parte integrante dela (Tese 2, p. 06).

A primeira é que ela não tem origem acadêmico-citatória, tampouco literária, como indica o cânone. Parece-nos um texto produzido pela própria autora especificamente para figurar como epígrafe na T2 (se assim não o fosse, haveria necessariamente referência, ainda que fosse um texto da própria autora, constante em publicação anterior). Para Bezerra (2007, p. 206), “a autoria do texto apresentado como epígrafe é sempre indicada, ressaltando precisamente o caráter de autoridade suprido pelo texto". Sem indicação autoral, somos levados a atribuir tal texto à produtora da T2 e a entender que ela se manifesta, sem rodeios, como autoridade no tema.

A segunda é que L2 se reporta especificamente ao público leitor surdo, projetado leitor modelo (ECO, 1990) da tese (O povo surdo (...) a sua história (...) você também constrói a história...). Em um tom notadamente incitativo ou convocatório, L2 sugere que as histórias surdas narradas na tese também compõem a história do leitor surdo, na mesma medida em que a história do leitor também compõe a história surda. Alerta-o para o fato de ser possível reconstruir tal história a partir da realização de sonhos surdos. 
Vemos em (02) um sujeito que ousa ao interpelar o leitor com o uso do pronome você, sem qualquer rodeio. Ora, o outro projetado pela epígrafe é o outro surdo (certamente não-militante, que necessita ser conscientizado, e não o outro ouvinte), em um olhar distinto daquele que considera o ouvinte o outro do surdo (PERLIN \& QUADROS, 2009). Embora a epígrafe não se volte exclusivamente (mas prioritariamente) para o público surdo, parecenos mais pertinente supor que tal epígrafe atinge com mais propriedade a comunidade surda, contemplada no tema da pesquisa.

Desse modo, a epígrafe parece funcionar como uma espécie de ressalva informativa ou inflamatória ao público leitor surdo, uma vez que, na tese, há histórias de horrores vivenciadas por surdos em uma instituição de ensino na década de 1960. Parafraseando a epígrafe, seria possível sustentar que L2 sugere que, com a construção coletiva de uma nova história, através da realização de sonhos surdos, as histórias de horror podem acabar e dar lugar a belas e novas histórias, escritas e trilhadas pelos surdos-leitores. Funcionar feito ressalva inflamatória pode ser uma justificativa para a necessidade de produção autoral da epígrafe, uma vez que não se veem aqui objetivos teóricos, mas introdutórios ao universo militante da pesquisa.

Questiono se seria possível determinar um lócus específico (academia ou comunidade) para a epígrafe acima e concluo que não. Ela é precisamente fruto do entrelaçamento necessário entre ser social e ser acadêmico. Fala de história (tema acadêmico), mas de um povo específico (surdos), incentivando ações na construção de um futuro melhor, postura definitivamente ativista. Diante disso, o éthos é hibridamente construído, apesar de, notadamente, prevalecer em destaque o éthos de liderança comunitária.

A epígrafe da T3 - de procedência acadêmica, sem título e com apenas um parágrafo - guarda mais semelhanças com a forma canônica de utilização de epígrafes em livros acadêmicos, ${ }^{8}$ se comparada com as duas anteriores, como se vê a seguir.

(03) Estoy consciente de lo que es ser sordo y estamos orgullosos de nosotros mismos como personas sordas, orgullosas de nuestra lengua y de nuestra cultura. Nuestra función como sordos nos permite tomar consciencia de nosotros mismos y respaldar nuestros iguales (Juan Eugenio Ravelo, de Mendonza (2003, p. 217) (T3, p. 07).

\footnotetext{
${ }^{8}$ Bezerra (2007) se utiliza da expressão "livro acadêmico" para se referir ao suporte de dissertações de mestrado e teses de doutorado.
} 
A epígrafe da T3, bem como o título da tese, veicula um simbólico nós, e parte de um autor surdo de reconhecida liderança política na América Latina: Eugenio Ravelo Mendonza, colombiano de nascimento e cosmopolita por opção (em seu blog, registram-se 42 países visitados, muitos deles a estudo ou a trabalho). Graduado e mestre, atualmente estudante de doutorado na Universidad de Deusto (Espanha), é professor de língua de sinais e incitador de discussões políticas relativas à comunidade surda sulamericana.

O caráter polifônico do excerto é acentuado pelo pronome nós, que inclui L3, surdo, na linha de ação enunciativa do autor citado, de forma a transformar L3 em coautor efetivo do enunciado, uma vez que o pronome plural o alça à posição de (co)locutor. À semelhança de um coral, cada voz surda acrescida parece fortalecer o coro da resistência. Certamente, se o autor da tese não fosse surdo, tal efeito de sentido não seria possível, pois o nós não seria aqui exclusivo (nós surdos: autor citado + autor citador).

No plano de conteúdo, vemos um autor surdo que, além de louvar a si e aos seus, dialogicamente resgata e nega, por meio de uma relação polêmica, uma formação discursiva (ou um posicionamento) que, hipoteticamente, faz o contrário, ou que, pelo menos, não vê a vida surda e seus atributos como um motivo de orgulho, segundo expressa a citação, mas sim de reforma, ajuste e disciplinamento. O posicionamento negado é advindo das ciências médicas, que também se faz presente no senso comum (estamos orgullosos de nosotros mismos). L3 deixa implícito que, semelhante ao autor citado, ele não precisa do aval dos ouvintes para respaldar sua forma de vida, mas sim do aval dos seus companheiros surdos, e age, inclusive, em extrema consonância com essa postura, trazendo a epígrafe de um autor surdo como ele, respaldando-o e sendo respaldado por ele concomitantemente. Semelhante à T2, o outro projetado aqui não é o ouvinte, mas o próprio povo surdo. Esse tom de autossuficiência, mesclado ao fato da citação ser de origem acadêmica, constrói uma imagem híbrida de um sujeito que se volta para a academia para trabalhar em prol dos seus, o que sugere uma ruptura no padrão de dominação ouvinte.

\footnotetext{
${ }^{9}$ Pesquisadores surdos (como os aqui focalizados) consideram o seu povo historicamente dominado pelos ouvintes. Considera-se que, em um processo correlato ao da colonização, ouvintes "ofereceram” aos surdos sua língua, cultura, visão de mundo e modelo educativo, além da autoimagem de sujeitos deficientes, forjada por séculos a partir de supostas limitações decorrentes da falta de audição.
} 
As epígrafes da T2 e da T3 têm em comum o fato de terem no público surdo tanto o seu foco produtivo quanto o seu aval. Na primeira, vemos uma interação verbal produzida de surdo para surdo, que transforma os leitores-ouvintes em plateia de um processo comunitário-social que se mostra autônomo e coerente. Na segunda, temos o louvor ao surdo e o respaldo na própria comunidade, que relativiza, nega ou se mostra indiferente (a) os respaldos dos ouvintes (Nuestra función como sordos nos permite tomar consciencia de nosotros mismos y respaldar nuestros iguales).

A relação que se pode estabelecer do cotejo entre as três epígrafes (e de algum conhecimento das teses) é que elas visam: i) demonstrar que se trata de uma produção acadêmica escrita por surdos e que é preciso não apenas explicitar tal fato, mas também, em diferentes proporções, reverenciá-lo; ii) Entende-se que tal relação é determinante para o desenvolvimento e o resultado do estudo a ser apresentado, isto é, apenas uma autoria de origem surda seria capaz de produzi-lo; iii) determinar que a produção acadêmica que virá é fruto do entrelaçamento entre um fazer acadêmico e um fazer ativista-social.

\section{Considerações Finais}

Epígrafes podem comunicar mais do que a filiação teórica. Podem indicar filiações políticas, filosóficas ou ideológicas. Podem sugerir ou eliminar planos de leituras. A pesquisa comprovou um fato já suspeitado e relatado neste estudo: obviamente, a elaboração de epígrafes não envolve a escolha de um simples adorno textual, mas a seleção minuciosa de um trecho que é representativo da semântica global do discurso que será apresentado.

As análises me levam a afirmar que a produção de imagens, deflagrada pelas epígrafes das teses selecionadas, situam-se mais no domínio do social do que no domínio da academia. Apesar de não ser essa uma constatação peremptória para toda a produção acadêmica de autoria surda, uma vez que se presencia nela uma fusão de lócus e imagens fundamentalmente híbridas, temos aqui um indício de que a intencionalidade e propósito comunicativo dos surdos na academia é o de reconstruir a imagem social dos surdos no meio social amplo, uma vez que as teses produzidas por surdos seguem uma forte ética de comprometimento com a causa do povo surdo.

É também a partir da construção de novas imagens de si que surdos se tornam autoridade em seus próprios fazeres e discursos e se veem, enfim, livres das amarras da dominação que a sociedade ouvinte, com ou sem 
intenção, coloca sobre eles. A pesquisa engendrada por surdos configurase, pois, representante autêntica de uma ciência dita pós-moderna, que se manifesta na erupção de um paradigma de racionalidade científica considerado emergente.

\section{Referências}

BEZERRA, B. G. Do manuscrito ao texto impresso: investigando o suporte. In: CAVALCANTE, M. M. et al. (Org.). Texto e discurso sob múltiplos olhares: gêneros e sequências textuais. Rio de Janeiro: Lucerna, 2007. p. 9-37.

BHATIA, V. K. Genre-mixing in academic introductions. English for Specific Purposes, v. 16, n. 3, p. 181-195, 1997.

CAVALCANTE, M.; CUSTÓDIO FILHO, V. Revisitando o estatuto do texto. Revista do Gelne, Teresina, v. 12, n. 2, p. 56-71, 2010.

DUCROT, O. O dizer e o dito. São Paulo: Pontes, 1987.

DUDLEY-EVANS, T. Genre analysis: an investigation of the introduction and discussions sections of MSc dissertations. In: COULTHARD, M. (Ed.). Talking about text. Birmingham: English Language Research, 1986. p. 128-145

FIORIN, J. L. Da necessidade da distinção entre texto e discurso. In: BRAIT, B.; SOUZA-E-SILVA, M. C. (Org.). Texto ou discurso. São Paulo: Contexto, 2012. v. 1, p. $145-165$.

GOMES, N. Intelectuais negros e a produção de conhecimento: algumas reflexões sobre a realidade brasileira. In: SANTOS, B. S.; MENEZES, M. P. (Org.). Epistemologias do Sul. São Paulo: Cortez, 2010. p. 492-518.

MAINGUENEAU, D. A propósito do ethos. In: MOTTA, A. R.; SALGADO, L. (Org.). Ethos discursivo. São Paulo, Contexto, 2008. p. 11-29.

MAINGUENEAU, D. Gênese dos discursos. São Paulo: Criar Ediçōes, 2005.

MAMA, A. Será ético estudar a África? Consideraçōes preliminares sobre pesquisa acadêmica e liberdade. In: SANTOS, B. S. MENEZES, M. P. (Org.). Epistemologias do Sul. São Paulo: Cortez, 2010. p. 603-637.

MARCUSCHI, L. A. Produção textual, análise de gêneros e compreensão. São Paulo: Parábola, 2008.

MIRANDA, W. A Experiência e a Pedagogia que nós surdos queremos. 2007. $153 \mathrm{f}$. Tese (Doutorado em Educação). Faculdade de Educação. Universidade Federal do Rio Grande do Sul, Porto Alegre. 2007. Disponível em: <http://www.lume.ufrgs. $\mathrm{br} / \mathrm{bitstream} / \mathrm{handle} / 10183 / 13581 / 000645759$.pdf? sequence=1>. Acesso em: 10 ago. 2013. 
QUADROS, R. M.; PERLIN, G. O ouvinte o outro do outro surdo In: II Seminário Internacional Educação Intercultural, Gênero e Movimentos Sociais, 2003, Florianópolis. Anais... Florianópolis: Fapeu-002, 2003. v.1. p. 617-627.

REZENDE, P. L. F. Implante Coclear na constituição dos sujeitos surdos. 2010. 164 f. Tese (Doutorado em Educação). Faculdade de Educação. Universidade Federal de Santa Catarina, Florianópolis, 2010. Disponível em: <http://repositorio. ufsc. $\mathrm{br} / \mathrm{bitstream} /$ handle/123456789/8545/281476.pdf?sequence=1>. Acesso em: 10 jan. 2013.

RIBEIRO, M. C. M. de A. O discurso acadêmico-científico produzido por surdos: entre o fazer acadêmico e o fazer militante. 2012. 262 f. Tese (Doutorado em Estudos Linguísticos). Faculdade de Letras. Universidade Federal de Minas Gerais, Belo Horizonte, 2012.

SANTOS, B. S. Um discurso sobre as ciências. Porto: Afrontamento, 2005.

SOULEZ, G. Ethos, enunciação, mídia: Semiótica do ethos. Revista Comunicação, mídia e consumo, n. 1. v. 2. Disponível em: <http://http://revcom.portcom. intercom.org.br/index.php/comunicacaomidiaeconsumo/article/view/5206>. Acesso em 20 ago. 2012.

STROBEL, K. L. Surdos: vestígios culturais não registrados na história. 2007. 176 f. Tese (Doutorado em Educação). Faculdade de Educação. Universidade Federal de

Recebido em 17/05/2013. Aprovado em 05/12/2013. 